\title{
Profile
}

\section{EURO DURG: the European Drug Utilization Research Group}

EURO DURG, the European Drug Utilization Research Group, is a multidisciplinary society bring-. ing together scientists from different disciplines, which aims to implement evidence-based information on rational drug use in daily practice in order to optimize the quality of drug use by understanding the determinants of prescribing behaviour.

EURO DURG had its origins as early as 1969, when an international group of scientists interested in tracking drug utilization patterns met in Oslo, Norway. For a long period it met informally at intervals under the auspices of the European Regional Office of the World Health Organization, and its members were largely responsible for WHO's book Drug Utilization Studies - Methods and Uses which appeared in 1993. In its present form, EURO DURG was constituted at a meeting held at Lake Balaton, Hungary, in 1996. It is in principle an association of national Drug Utilization Research Groups, which have been established in Italy, Germany, Belgium, Sweden, The Netherlands, Czech Republic, United Kingdom, Spain and Denmark. Working groups have been set up to deal with mapping Drug Utilization in Europe (Prof. Nicola Monenaro, Italy), the link between Drug Utilization and Quality Assurance (Prof. Ulf Bergman, Sweden and Dr Hugh McGavock, UK) and Patient Perspectives (Prof. Ebba Holme Hansen, Denmark and Dr Emilio Sanz, Spain). A fourth group, coordinated by Dr Kåre Øydvin, Norway, has developed and updated the ATC/DDD methodology which provides a system of classification of drugs and a unit for the measurement of drug utilization in a manner which renders international comparisons possible despite differences in nomenclature, packaging sizes, pricing and customary dosages.

In those countries where a national Drug Utilization Research Group has not yet been set up, EURO DURG accepts individuals as members.

Following its first meeting in Hungary, with 250 participants from 35 countries, Prof. Flora Haaijer Ruskamp (Groningen, The Netherlands), was appointed President of EURO DURG, and an Executive Committee was elected for the period 1996-1998. The next scientific meeting of EURO DURG will be held in Berlin on 16 and 17 September 1997, followed by a joint symposium with the European Association for Clinical Pharmacology and Therapeutics.

Enquiries from scientists interested in joining EURO DURG can be sent to:

Prof. Ulf Bergman,

The Secretariat EURO DURG,

WHO Collaborating Centre for Drug Utilization Research and Clinical Pharmacological Services,

Karolinska Institute,

Huddinge University Hospital,

S-14186 Huddinge,

Sweden.

Tel.: +468585811 96; fax: +468585810 70; email: Ulf.Bergman@pharmlab.hs.sll.se. 